UDC 532:[612+613]

\title{
3D-MODELING OF ANTRODUODENAL ZONE MOTILITY OF DIGESTIVE TRACK FOR THE PURPOSE OF HEALTH RISKS EVALUATION WITH PERORAL EXPOSITION TO CHEMICALS*
}

\section{M.R. Kamaltdinov}

Federal Budget Scientific Institution "Federal Scientific Center for Medical and Preventive Health Risk Management Technologies", Russian Federation, Perm, 82 Monastyrskaya St., 614045 Federal State Budgetary Educational Institution of Higher Professional Education "Perm State National Research Polytechnic University”, Russian Federation, Perm, 29 Komsomolsky av., 614990

Abstract. As a part of multi-level model of accumulation of functional disorders in the human body under the influence of environmental factors, the sub-model of "meso-level" of digestive system is being developed. The article highlights the tasks of reconstruction of 3D model of antroduodenal area of the gastrointestinal tract and evaluation of nodes dislocation of the computational grid at the passing of peristaltic wave in gastric antrum and pyloric sphincter motor activity. The observed approaches could be applied in health risk assessment at peroral exposure to chemicals.

Key words: mathematical modeling, digestive system, stomach, evolution of functional disorders, peristaltic waves.

A multi-level mathematical model is developed to evaluate the impact of environmental factors on public health and forecast the development of functional disorders in a human body associated with the chemical, physical, social and other factors [8]. The upper level (or 'macro level') of the accumulated functional disorders model - an entire body, the second level (or 'meso-level') is individual organs and systems. Based on the suggested multi-level model, various approaches to the assessment of the integral and population health risk were developed $[1,4,5]$ as well as methods to calculate additional cases of diseases and deaths associated with the environmental factors [2].

The need to determine kinetic dependencies for the chemical substances originating from food products and drinking water explains the practicability of development of a submodel of the digestive tract 'meso-level'. In peroral exposure to chemical substances, one can point out two mechanisms of the digestive tract disorders risk evolution - the irritant effect of the chemical substances contained in the digestive tract on the tract wall, and the negative impact of the chemical substances contained in blood that washes off the digestive tract organs.

(C) Kamaltdinov M.R., 2014

Kamaltdinov Marat Rashidovich - Junior research fellow of Department (e-mail: kamaltdinov@fcrisk.ru; ph: +7 (342) 237-18-04). 
Besides, the substances that come into the body through the gastro-intestinal tract via the circulatory system may impact other organs and systems thus increasing the risk of health disorders. For this reason, in order to assess health risks in peroral chemical exposure within the framework of evolutionary modelling, it is necessary to do dynamic calculations of the concentrations in the GIT chamber.

It should be noted that the above task requires a certain level of development of the submodel of digestive system on the macro level and the submodels of the meso-level - mouth cavity, gastro, intestine tract which as a whole present a rather major issue. In that regard, the article reviews only a small extract from the research devoted to one of the most interesting smaller tasks - 3D modelling of the flow in the antroduodenal stomach chamber with due consideration of peristaltic waves.

Today when experimental research methods are constantly improving especially in terms of the quality of images of digestive system organs and systems (quite often over time thus allowing to track the processes over time), interdisciplinary approaches to the application of mathematical modelling methods in physiology, biology and biochemistry of digestion are rapidly developing. Kinetic compartmental models [6, 7] widely used for the assessment of the substance concentrations in the circulatory, digestive and other systems do not track spatial characteristics of the process because they are mostly based on the system of standard differential equations with a time variable. In this context, it is reasonable to assess the chemical substances taken in perorally with the help of the continuum mechanics method (hydrodynamics) using the differential equations in partial derivatives that describe spatiotemporal patterns. One of the advantages of such approach is physiology focus - ability to model the main digestive processes including absorption and secretion (diffusion processes), movements of the tract walls, splitting and dilution of food, and biochemical reactions in the GIT chamber.

Despite the fact that in the last several decades, new approaches to the numerical simulation of the flow process in various digestive tract regions - esophagus, gastro and bowelhave been developing, the number of 3-D models is still very limited [14, 24, 27]. The biggest interest from the point of view of mechanics is drawn to the models of the flow in the antroduodenal region of the tract $[9,12]$ since this region has the most pronounced effects of intermixing, homogenization of the mixture determined by intensive motor activity of the muscle walls [17]. Studies on this topic require further development - taking into account the above main digestive processes as well as neuroendocrinal regulation and functional disorders of the body organs. 
Currently, the 'meso-level' model of the digestive system has helped introduce the basic terms and definitions, develop the main concepts and paths for further development of submodels including a transition to the 3-D objective [8]. This article briefly describes the approaches to the reconstruction of a 3-D shape of the antroduodenal region of the gastrointestine tract and to the definition of the grid point shifts when passing through a contraction wave in the antral section and the motor activity of the pyloric sphincter.

Experimental methods - ultrasound (USG) and magnetic resonance imaging (MRI) allow us to take high resolution pictures of internal organs in different sections with a small time interval. MRI results are used to determine a particle size, track the tract motor activity and gastric emptying rate $[16,22]$. The main disadvantages of MRI include a high cost of equipment; in addition, a survey is carried out in the prone position, in which the distribution of food in the tract is different in comparison with the sitting and standing position. [13] The results of ultrasound are used to construct geometric shapes and evaluate gastrointestinal motor performance $[10,26]$, with this if the three-dimensional shape recovery methods for twodimensional images of MRI and ultrasound are well developed [11, 18, 20, 21, 24], then for pa eristaltic wave simulation it is desirable to have an analytical description of the surface of the body. Due to interindividual variability of sizes and shapes of the digestive tract [22], to construct a simplified surface of the antroduodenal sector it would be sufficient to have evidence of anatomical atlases; nonetheless the parameters of motor activity (especially in functional disorders) should be determined from experiment.

Let us briefly review the algorithm for the reconstruction of a three-dimensional shape of the antroduodenal section of the gastrointestinal tract based on the ultrasound results.

1. The geometric shape of the modelled object includes the antrum of the stomach and a small sector of the adjacent duodenum. We obtained ultrasound images of the stomach (vertical position of the human body) in planes parallel to the two main anatomical planes: horizontal (parallel to the ground level) and middle (separating the human body into two symmetrical halves). At a first approximation, we estimated the size of the stomach and defined the reference points on the concave and convex part of the antral section in the third main (front) anatomical section (plane XY). Concave and convex walls of the stomach in the XY plane were approximated by polynomials of the $6^{\text {th }}$ degree.

2. The central line of the antrum is defined as the mean between the curves approximating the concave and convex wall of the stomach; it is located in the XY plane and is approximated by a polynomial of the $6^{\text {th }}$ degree. 
3. The next step involves construction of a finite number ellipses of variable radii, which will be the basis for the approximation of a three-dimensional surface of the stomach; the centers of ellipses lie on the center line, and the ellipse lies in the normal plane (normal to the plane of the spatial curve is a plane perpendicular to the tangent line and passing through the point of contact) to the center line. The major axis of the ellipse $r_{1}$ lies in $X Y$ plane, the minor axis $r_{2}$ is perpendicular to the $X Y$ plane, the ratio of $r_{1}$ and $r_{2}$ in the antrum and the gastric outlet sector is considered constant and equals 0.613 (the measurement is based on the ultrasound results).

4. The calculated coordinates of the reference ellipses are exported to Ansys Design Modeler, and a three-dimensional approximation of the surface is conducted using the skin / loft tool (Fig. 1).

The segment with the smallest radius corresponds to the pyloric sphincter. The major axis of the elliptical cross-section segment $r_{1}$ varies sinusoidally, in which the parameters corresponding to the open / closed state of the sphincter are introduced (which corresponds to a change in the diameter of the pyloric opening in the $X Y$ plane at the narrowest point of 0.00923 to $0.00102 \mathrm{~m}$ ). Complete closing of the sphincter is modeled with a small hole to ensure the existence of solutions of the equations of fluid flow and stability of the numerical calculations of the pyloric opening. In the future, additional criteria on the state of the sphincter (a sufficient degree of grinding food, acidity) should be introduced. The central line of the intestine at a first approximation is described by a quadratic dependence on the coordinate $x$, the radius $r_{1}$ and $r_{2}$ vary linearly to a value of $0.014 \mathrm{~m}$, so the cross section on the left border of intestines takes a circular shape that corresponds to the anatomical reference data.

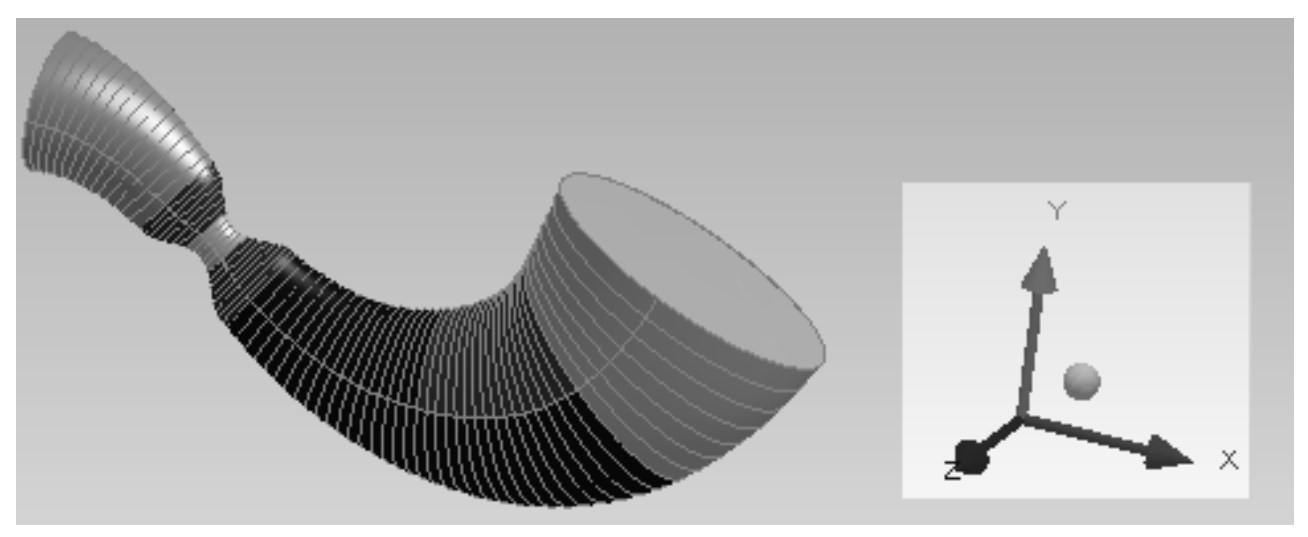

Fig. 1 Construction of a three-dimensional surface of the stomach in Ansys Design Modeler (abbreviated segment the region of the pyloric opening, segment to the left of the reduction - the intestine, to the right - the antrum) 
5. A computational grid of 717,953 tetragonal elements was built in Ansys Meshing. The edge of the surface element varies from $0.6 \mathrm{~mm}$ (in the areas of the concave segment of the antrum and pyloric region near the hole) to $1.5 \mathrm{~mm}$ (in the convex part of the antrum).

Wave propagation and interaction with the pyloric sphincter motility is modeled on the basis of published data $[15,19]$ and the ultrasound results. A few minutes after a meal, contraction waves begin to spread in the antrum - compression of the sections (strips) of the circular muscle layer around the entire circumference of the stomach. Following the contraction of the area of the circular muscle is their relaxation, and the contraction wave moves to another sector. The antral contraction wave is initiated from the ellipse centered at $x=0,088 \mathrm{~m}$ and is moving to the pyloric opening at a rate of $v=2,2 \cdot 10^{-3} \mathrm{~m} / \mathrm{s}$, directed along the tangent to the center line, for 38 seconds.

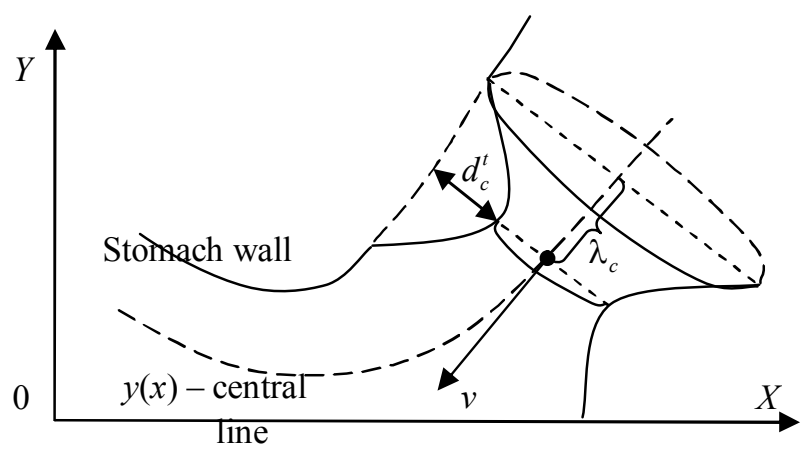

Fig. 2 Options wave contraction in the antrum $2 \cdot 10^{-3} \mathrm{~m} / \mathrm{s}$ tangential to the center line, for 38 seconds.

The values of the wave parameters (Fig. 2) in the baseline scenario: the wave width parameter does not depend on time $\lambda_{c}=0,01 \mathrm{~m}$ (half of the wave width), the contraction amplitude is linearly growing during the first $12 \mathrm{~s}$ to the value $0.011 \mathrm{~m}\left(d_{c}^{t}=(t / 12) \cdot 0,011 \mathrm{~m}\right)$, at the moment of time $t \in[12,34] \mathrm{s}$ the amplitude remains constant, at $t \in[34,38] \mathrm{s}$ is linearly decreasing to 0 . The period of wave initiation is $18 \mathrm{~s}$. The sphincter opens at $t \in[26,28] \mathrm{s}$, and closes at $t \in[30,32] \mathrm{s}$ (Fig. 3).
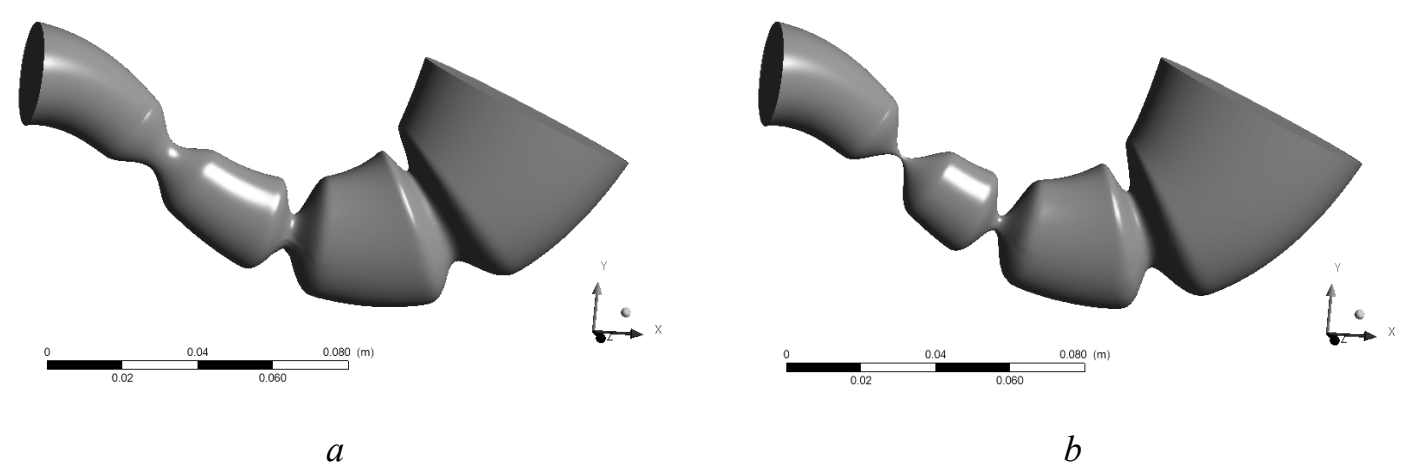

Fig. The position of 3 waves in the antrum: a - when the pyloric sphincter is open; $\mathrm{b}-$ when the pyloric sphincter is closed 
Dynamic rebuilding of the the computational grid is conducted by using the Dynamic Mesh tools in Fluent solver using a script (User-Defined Function), written in C. A script is a software implementation of a three-dimensional algorithm of the grid point shift assessment during a moving wave of antral contractions and motility of the pyloric sphincter. The main step of the algorithm is to determine the position of the points in the estimated time through a shift from an unstrained state along the perpendicular to the center line using a sinusoidal function:

$$
\begin{gathered}
d_{\text {node }}^{t+1}=\left(r_{\text {node }} / r_{1 \text { node }}\right) \cdot d_{c}^{t+1} \cdot \\
\cdot\left(1+\sin \left(\pi \cdot \frac{\lambda_{c}-\rho_{c}}{2 \lambda_{c}}\right)\right)^{2} / 2, \text { when } \rho_{c} \leq \lambda_{c}
\end{gathered}
$$

where $d_{\text {node }}^{t+1}-$ is a shift value, $\rho_{c}-$ is a distance between the center of the ellipse and the position of the center of the wave, $r_{1 \text { node }}-$ a major radius of the ellipse in the initial configuration, $r_{\text {node }}-$ radius of the ellipse in the initial configuration corresponding to the grid point. Raising of the multiplier with sine to the power (in this case, to the second power) determines smoothing in the wave peak region.

Thus, in the framework of the "meso-level" digestive system, we developed an algorithm to construct a three-dimensional shape of the antroduodenal area of the gastrointestinal tract based on the ultrasound result. We estimated the changes in the configuration of the computational grid points for the contraction wave passing through the antral and pyloric sphincter motor activity. The results of the study will be used to calculate the three-dimensional flow field in the antroduodenal region of the tract. Further development of the "meso-level" model involves consideration of a multiphase flow (particles of food / liquid), the processes of secretion of the digestive juice, absorption of toxic substances into the circulatory system, and the elements of the neuroendocrine regulation. Furthermore, these objectives require further development of other submodels of the digestive system, especially the intestine where the process of substance absorption into the circulatory system dominates. The above approaches can be used to assess the health risk associated with oral chemical exposure in an evolutionary simulation.

\section{References}

1. Kamaltdinov M.R., Kir'janov D.A. Primenenie rekurrentnyh sootnoshenij dlja ocenki integral'nogo riska zdorov'ju naselenija [Application of recurrence relations for the evaluation of the integral risk to public health]. Zdorov'e sem'i - 21 vek, no. 3. Available at: http://www.fh21.perm.ru/download/2011-3-6.pdf. 
2. Kir'janov D.A., Kamaltdinov M.R. Metodika rascheta dopolnitel'noj zabolevaemosti i smertnosti na osnove jevoljucionnogo modelirovanija riska zdorov'ju naselenija [Methods of calculating the additional morbidity and mortality based on evolutionary modeling of health risk]. Analiz riska zdorov'ju, 2014, no. 1, pp. 31-39.

3. Trusov P.V., Zajceva N.V., Kir'janov D.A., Kamaltdinov M.R., Cinker M.Ju., Chigvincev V.M., Lanin D.V. Matematicheskaja model' jevoljucii funkcional'nyh narushenij v organizme cheloveka $\mathrm{s}$ uchetom vneshnesredovyh faktorov [Mathematical model of the evolution of functional disorders in the human body, taking into account environmental factors]. Matematicheskaja biologija $i$ bioinformatika, 2012, no. 2, pp. 589-610. Available at: http://www.matbio.org/2012/Trusov_7_589.pdf.

4. Zajceva N.V., Shur P.Z., Kir'janov D.A., Kamaltdinov M.R., Cinker M.Ju. Metodicheskie podhody k ocenke populjacionnogo riska zdorov'ju na osnove jevoljucionnyh modelej [Methodological approaches to the assessment of public health risk on the basis of evolutionary models]. Zdorov'e naselenija i sreda obitanija, 2013, no. 1 (238), pp. 4-6.

5. Zajceva N.V., Trusov P.V., Shur P.Z., Kirjanov D.A., Chigvincev V.M., Cinker M.Ju. Metodicheskie podhody $\mathrm{k}$ ocenke riska vozdejstvija raznorodnyh faktorov sredy obitanija na zdorov'e naselenija na osnove jevoljucionnyh modelej [Methodological approaches to assessing the risk of exposure to diverse environmental factors on human health based on evolutionary models]. Analiz riska zdorov'ju, 2013, no. 1, pp. 15-23.

6. Samura B.A., Dralkin A.V. Farmakokinetika [Pharmacokinetics]. Kharkiv: "Osnova", 1996. $286 \mathrm{p}$.

7. Solov'ev V.H., Firsov A.A., Filov V.A. Farmakokinetika [Pharmacokinetics]. Moscow: Medicina, 1980. $432 \mathrm{p}$.

8. Trusov P.V., Zajceva N.V., Kamaltdinov M.R. Modelirovanie pishhevaritel'nyh processov $\mathrm{s}$ uchetom funkcional'nyh narushenij $\mathrm{v}$ organizme cheloveka: konceptual'naja $\mathrm{i}$ matematicheskaja postanovki, struktura modeli [Modeling digestive processes taking into account functional disorders in the human body: conceptual and mathematical formulations, structure of the model]. Rossijskij zhurnal biomehaniki, 2013, no. 4, pp. 67-83.

9. Kozu H., Kobayashi I., Nakajima M., Uemura K., Sato S., Ichikawa S. Analysis of flow phenomena in gastric contents induced by human gastric peristalsis using CFD. Food Biophysics, 2010, vol. 5, pp. 330-336.

10. Liao D., Gregersen H., Hausken T., Gilja O.H., Mundt M., Kassab G. Analysis of surface geometry of the human stomach using real-time 3D ultrasonography in vivo. Neurogastroenterol Motil, 2004, vol. 16, pp. 315-324.

11. Barequet G., Shapiro D., Tal A. Multilevel sensitive reconstruction of polyhedral surfaces from parallel slices. The Visual Computer, 2000, vol. 16, pp. 116-133.

12. Dillard S., Krishnan S., Udaykumar H.S. Mechanics of flow and mixing at antroduodenal junction. World J Gastroenterol, 2007, vol. 1, pp. 1365-1371.

13. Jones K.L., O’Donovan D.G., Horowitz M., Russo A., Lei Y., Hausken T. Effects of posture on gastric emptying, transpyloric flow, and hunger after a glucose drink in healthy humans. Dig Dis Sci, 2006, vol. 51, pp. 1331-1338.

14. Ferrua M.J, Singh R.P. Modeling the fluid dynamics in a human stomach to gain insight of food digestion. Journal of food science, 2010, vol. 75, pp. 151-162.

15. Pal A., Indireshkumar K., Schwizer W., Abrahamsson B., Fried M., Brasseur J. G. Gastric flow and mixing studied using computer simulation. Proc. R. Soc. Lond. B, 2004, vol. 271, pp. 2587-2594.

16. Marciani L., Gowland P.A., Spiller R.C., Manoj P., Moore J.R., Young P., Al-Sahab S., Bush D., Wright J., Fillery-Travis A.J. Gastric response to increased meal viscosity assessed by echo-planar magnetic resonance imaging in humans. The journal of nutrition, 2000, vol. 130, pp. $122-127$.

17. Kong F., Singh R.P. Disintegration of solid foods in human stomach. Journal of food science, 2008, vol. 73, pp. 67-80. 
18. Lobregt S., Viergever A. A discrete dynamic contour model. IEEE transactions on medical imaging, 1995, vol. 14, pp. 12-24.

19. Pal A., Brasseur J. G, Abrahamsson B. A stomach road or "Magenstrasse" for gastric emptying. Journal of Biomechanics, 2007, vol. 40, pp. 1202-1210.

20. Nedzvezd A., Lukashevich P., Ablameyko S., Deserno T. M., Lehmann. Reconstruction of 3D medical object shapes from 2D cross-sections. Pattern recognition and information processing: proceedings of the tenth international conference. Editors: Krasnoproshin V., Ablameyko S., Sadykhov R. 2009, pp. 247-250.

21. Rohling R.N. 3D freehand ultrasound: reconstruction and spatial compounding. PhD Dissertation. University of Cambridge, 1998. 158 p.

22. Schulze K. Imaging and modeling of digestion in the stomach and the duodenum. Neurogastroenterol Motil, 2006, vol. 18, pp. 172-183.

23. Feinle C., Kunz P., Boesiger P., Fried M., Schwizer W. Scintigraphic validation of a magnetic resonance imaging method to study gastric emptying of a solid meal in human. Gut, 1999, vol. 44, pp. 106-111.

24. Singh S., Singh R.P. Gastric Digestion of Foods: Mathematical Modeling of Flow Field in a Human Stomach. Food Engineering Interfaces, 2011, pp. 99-117.

25. Treece G.M. Volume measurement and surface visualisation in sequential freehand 3D ultrasound. PhD Dissertation. University of Cambridge, 2000. 172 p.

26. Frokjaer J.B., Andersen S.D., Drewes A.M., Gregersen H. Ultrasound-determined geometric and biomechanical properties of the human duodenum. Dig. Dis. Sci., 2006, vol. 51, pp. $1662-1669$.

27. Xue Z., Ferrua M.J., Singh R.P. Computational fluid dynamics modeling of granular flow in human stomach. Alimentos hoy, 2012, vol. 21, pp. 3-14. 